\title{
The effects of tourniquet use on blood loss in primary total knee arthroplasty for patients with osteoarthritis: a meta-analysis
}

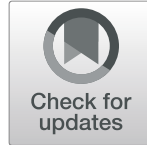

\author{
D. F. Cai ${ }^{*}$, Q. H. Fan, H. H. Zhong, S. Peng and H. Song
}

\begin{abstract}
Background: The tourniquet is a common medical instrument used in total knee arthroplasty (TKA). However, there has always been a debate about the use of a tourniquet and there is no published meta-analysis to study the effects of a tourniquet on blood loss in primary TKA for patients with osteoarthritis.

Methods: We performed a literature review on high-quality clinical studies to determine the effects of using a tourniquet or not on blood loss in cemented TKA. PubMed, Web of Science, MEDLINE, Embase, and the Cochrane Library were searched up to November 2018 for relevant randomized controlled trials (RCTs). We conducted a meta-analysis following the guidelines of the Cochrane Reviewer's Handbook. We used the Cochrane Collaboration's tool for assessing the risk of bias of each trial. The statistical analysis was performed with Review Manager statistical software (version 5.3).

Results: Eleven RCTs involving 541 patients (541 knees) were included in this meta-analysis. There were 271 patients (271 knees) in the tourniquet group and 270 patients ( 270 knees) in the no tourniquet group. The results showed that using a tourniquet significantly decreased intraoperative blood loss $(P<0.002)$, calculated blood loss $(P<0.002)$, and the time of operation $(P<0.002)$, but tourniquet use did not significantly decrease postoperative blood loss $(P>0.05)$, total blood loss $(P>0.05)$, the rate of transfusion $(P>0.05)$, and of deep vein thrombosis (DVT) $(P>0.05)$ in TKA.

Conclusions: Using a tourniquet can significantly decrease intraoperative blood loss, calculated blood loss, and operation time but does not significantly decrease the rate of transfusion or the rate of DVT in TKA. More research is needed to determine if there are fewer complications in TKA without the use of tourniquets.
\end{abstract}

Keywords: Total knee arthroplasty, Tourniquet, Blood loss, Complications

\section{Introduction}

The tourniquet is a common medical instrument used in total knee arthroplasty (TKA). A recent study of the American Association of Hip and Knee Surgeons found that approximately $95 \%$ of surgeons used tourniquets during TKA [1]. However, there has always been a debate about the pros and cons of tourniquet use [2]. For supporters, the tourniquet has several advantages in TKA: (1) a tourniquet can provide a bloodless field of view for surgery, (2) a tourniquet may help reduce

\footnotetext{
* Correspondence: caidongfeng1688@163.com

Department of Orthopaedic Surgery, Affiliated Hospital of Zunyi Medical College, 149 Dalian Road, Huichuan District, Zunyi City, Gui Zhou Province,
} China

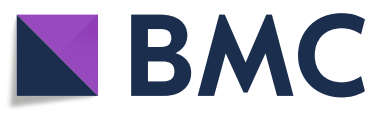

() The Author(s). 2019 Open Access This article is distributed under the terms of the Creative Commons Attribution 4.0 International License (http://creativecommons.org/licenses/by/4.0/), which permits unrestricted use, distribution, and reproduction in any medium, provided you give appropriate credit to the original author(s) and the source, provide a link to the Creative Commons license, and indicate if changes were made. The Creative Commons Public Domain Dedication waiver (http://creativecommons.org/publicdomain/zero/1.0/) applies to the data made available in this article, unless otherwise stated. tion, and (3) a tourniquet could also shorten the operation time [3]. The disadvantages of tourniquet use mainly include damaging blood vessels and local soft tissue and increasing fibrinolytic activity [4]. Although tranexamic acid can decrease fibrinolytic activity, when combined with the use of a tourniquet, fibrinolytic activity will increase [5]. A tourniquet can also lead to local tissue swelling or hypoxia, which then affects wound healing [6-8] and produces more pain in the immediate post-operative surgery $[3,9]$. Applying a tourniquet to the quadriceps femoris can affect the intraoperative patellar tracking and disturb the surgeon's judgment of this movement. Tourniquets are also thought to be 
associated with an increased risk of deep vein thrombosis (DVT), wound infection or poor healing, postoperative dysfunction, and increased blood loss [7]. Moreover, some studies found that the use of a tourniquet may increase postoperative hidden blood loss [10].

There is no agreement on the pros and cons of tourniquet use in TKA. Some researchers wanted to gather reliable evidence by integrating high-quality clinical trial data. However, their results were not convincing, because the included patients had different primary diseases, such as rheumatoid arthritis, osteoarthritis, and even patients with revision, and different primary diseases may contribute to the incidence of complications and produce bias [11].

For these reasons, the conclusions of these metaanalyses need further support. Additionally, there is no published meta-analysis to study the effects of a tourniquet on blood loss in primary TKA for patients with osteoarthritis. Therefore, we aimed to assess the effect of tourniquet use on reducing blood loss and to determine the possible risks of using a tourniquet in primary TKA for patients with osteoarthritis.

\section{Materials and methods}

\section{Search strategy}

Our research began on September 1, 2018. The electronic databases of PubMed, Web of Science, MEDLINE, Embase, and the Cochrane Library were screened up to November 2018. The following keywords were used in the search: "total knee arthroplasty," "total knee replacement," "TKA," "TKR," "tourniquet," and "randomized controlled trial." Boolean operators were used to combine the terms. Reference lists of the relevant papers, especially papers included in the published meta-analyses, were screened. No restriction was made for publication status or language.

\section{Study inclusion and exclusion criteria}

This meta-analysis was based on the guidelines described in the Cochrane Handbook for Systematic Reviews of Interventions [12]. We included literature according to the following criteria: (1) randomized controlled trials (RCTs) that compared patients undergoing primary TKA with or without the use of a tourniquet and (2) trials in which the patients received TKA for osteoarthritis. The exclusion criteria were as follows: studies that included a different tourniquet application strategy or revision TKA, studies in which patients received TKA for rheumatoid arthritis, animal studies, and duplicate studies or data. Two of the authors (DF Cai and $\mathrm{QH}$ Fan) independently scanned the titles and abstracts of all relevant studies and selected the RCTs according to the inclusion and exclusion criteria. If there were discrepancies regarding study inclusion, a third reviewer (Song $\mathrm{H}$ ) was consulted, and the disagreement was resolved through discussion.

\section{Data extraction}

Two of the authors (DF Cai and QH Fan) independently extracted relevant data based on a well-designed data extraction format that contains manuscript information, participant demographics, clinical outcomes, and any recorded complications. The clinical outcomes included total blood loss; calculated blood loss, which was calculated by the methods described by Gross [13] and thought to represent the true loss of blood; postoperative blood loss; intraoperative blood loss; blood transfusion volume; and blood transfusion rate. Recorded complications included any kind of wound complications, muscle or nerve injury, DVT, and pulmonary embolism (PE).

Discrepancies on data extraction were resolved by consulting another investigator (Song $\mathrm{H}$ ); if the authors failed to reach a consensus, discrepancies were resolved by group discussion.

\section{Risk of bias}

Two independent researchers (DF Cai and QH Fan) assessed the risk of bias of each included RCT by using the risk assessment tool recommended by the Cochrane Reviewer's Handbook 5.1.0 [14]. The assessment scale includes six domains: sequence generation, allocation concealment, blinding, incomplete outcome data, selective outcome reporting, and other potential threats to validity.

Any discrepancies in the risk assessment were resolved by consulting another investigator (Song $\mathrm{H}$ ); if failing to reach a consensus, discrepancies were resolved by group discussion.

\section{Statistical analysis}

The analysis was conducted using Review Manager statistical software (version 5.3, Copenhagen: The Nordic Cochrane Centre, The Cochrane Collaboration, 2014). For continuous outcome data, a weighted mean difference (WMD) and 95\% confidence interval (CI) were calculated by means and standard deviations (SDs). For dichotomous outcomes, the risk ratio or relative risk (RR) and 95\% CI were calculated as the summary statistics. Statistical heterogeneity was determined by the chisquare test and $I^{2}$. A value of $I^{2}<25 \%$ indicated low statistical heterogeneity; $25 \% \leq I^{2}<50 \%$ indicated moderate statistical heterogeneity; and $50 \% \leq I^{2}<75 \%$ indicated high statistical heterogeneity [15]. $P<0.05$ was considered to be statistically significant. A random-effects analysis was used to synthesize heterogeneous data, and a fixed-effects analysis was used to synthesize data when the data were not heterogeneous [16]. 


\section{Result}

\section{Selection process of the included studies}

By comprehensive review of the electronic databases, a total of 1535 articles were initially identified. Of these, 194 articles were from PubMed, 598 articles were from Web of Science, 512 articles were from MEDLINE, 203 articles were from Embase, and 28 articles were from the Cochrane Library. A total of 547 articles were excluded as duplicates, and 956 articles were excluded by scanning the titles and the abstracts. After reading the full texts, 11 articles were excluded since they only compared the effects of releasing tourniquet after wound closure with those before wound closure, and 10 articles were excluded because patients with different primary diseases were included. Finally, a total of 11 articles including 541 patients (541 knees) were included in this meta-analysis [17-27]. There were 271 patients (271 knees) in the tourniquet group and 270 patients (270 knees) in the no tourniquet group. A flowchart of RCT selection is shown in Fig. 1, and the characteristics of the included articles are shown in Table 1.
Risk of bias assessment

In eight RCTs [17, 18, 20-22, 24-27] of those included, the methods of randomization were described, and the allocation of patients was concealed by using sealed envelopes. None of the studies blinded the surgeons. Seven RCTs [20-22, 24-27] involved blinding of the outcome assessments. All but one RCT [25] afforded complete outcome data, and none of the included RCTs exhibited selective outcome reporting. The results are summarized in Fig. 2.

\section{Clinical outcome measures}

Among the included studies, five [17, 19, 21, 22, 27] provided data on intraoperative blood loss. There was a significant difference between groups in terms of intraoperative blood loss, and the pooled data showed that application of a tourniquet decreased intraoperative blood loss by $143.55 \mathrm{~mL}$ (WMD $=-143.55 \mathrm{~mL}$; 95\% CI, 204.59 to $\left.-82.52 ; n=234 ; P<0.00001 ; I^{2}=94 \%\right)$, as shown in the forest plot (Fig. 3 ).

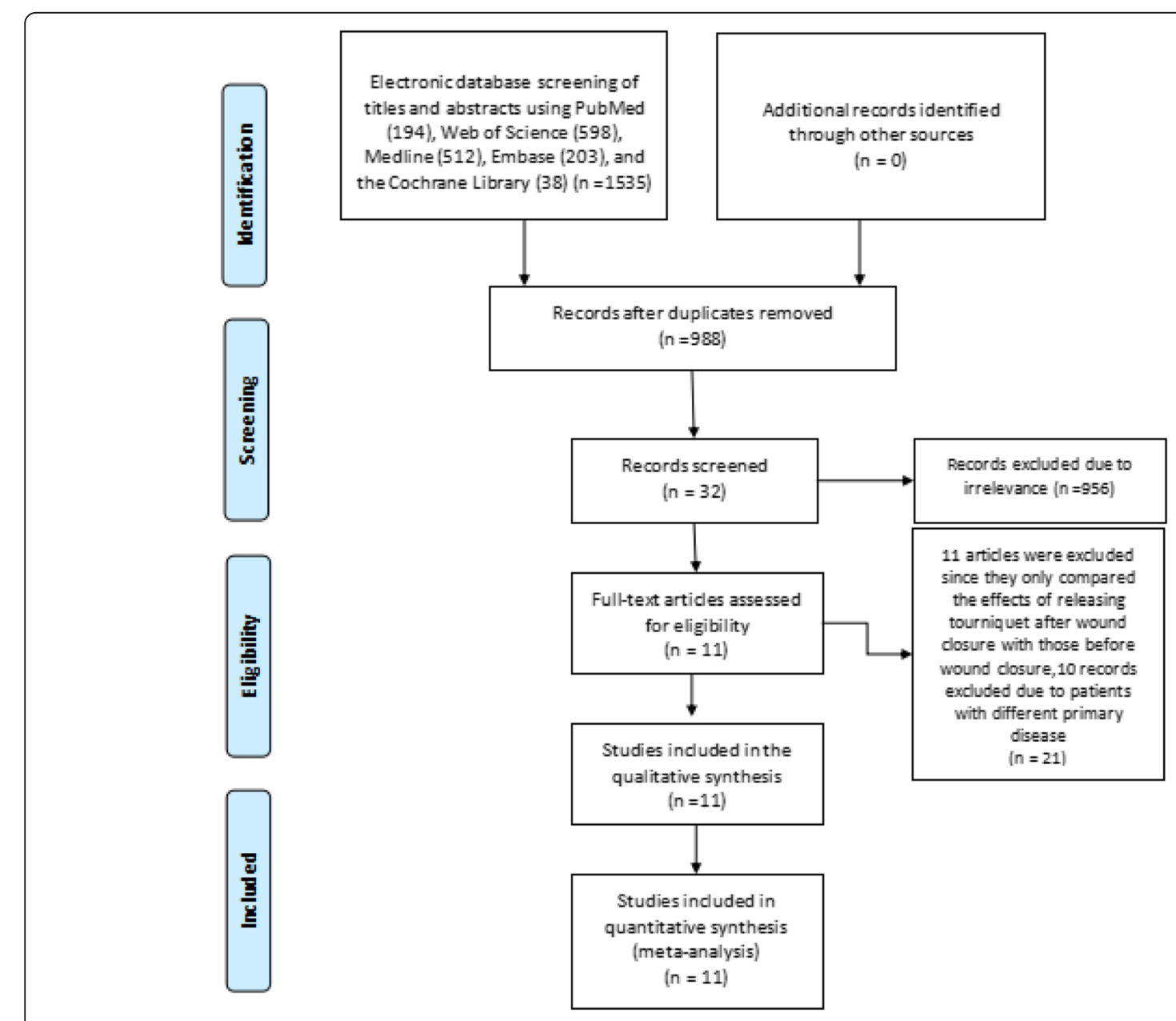

Fig. 1 Flowchart showing the selection process of randomized controlled trials 
Table 1 Characteristics of the included articles

\begin{tabular}{|c|c|c|c|c|c|c|c|c|c|c|c|c|c|c|}
\hline \multirow[t]{2}{*}{ Study } & \multirow[t]{2}{*}{ Year } & \multicolumn{2}{|c|}{$\begin{array}{l}\text { Sample } \\
\text { size }\end{array}$} & \multicolumn{2}{|c|}{$\operatorname{Sex}(M / F)$} & \multicolumn{2}{|c|}{$\begin{array}{l}\text { Mean } \\
\text { age } \\
\text { (years) }\end{array}$} & \multicolumn{2}{|c|}{$\begin{array}{l}\mathrm{BMI}(\mathrm{kg} / \\
\left.\mathrm{m}^{2}\right)\end{array}$} & \multirow[t]{2}{*}{ Cemented } & \multirow[t]{2}{*}{ Prosthesis type } & \multirow[t]{2}{*}{$\begin{array}{l}\text { Patellar } \\
\text { resurfacing }\end{array}$} & \multirow[t]{2}{*}{ Thromboprophylaxis } & \multirow[t]{2}{*}{ Hemostasis } \\
\hline & & $\overline{\mathrm{T}}$ & $\mathrm{NT}$ & $\overline{\mathrm{T}}$ & NT & $\mathrm{T}$ & NT & $\overline{\mathrm{T}}$ & NT & & & & & \\
\hline P. Aglietti & 1999 & 10 & 10 & $3 / 7$ & $4 / 6$ & 70.0 & 68.0 & 27.9 & 27.3 & Y & M.B.K, Zimmer & NS & NS & NS \\
\hline $\begin{array}{l}\text { H.M. } \\
\text { Wakankar }\end{array}$ & 1999 & 37 & 40 & $\begin{array}{l}11 / \\
26\end{array}$ & $\begin{array}{l}14 / \\
26\end{array}$ & 72.5 & 71.8 & NS & NS & Y & Insall-Burstein & Y & Warfarin & NS \\
\hline Eric Vanden & 2002 & 40 & 40 & $9 / 31$ & $\begin{array}{l}16 / \\
24\end{array}$ & 72.5 & 68.5 & NS & NS & Y & Wallaby I, Protek & NS & NS & NS \\
\hline G. Matziolis & 2005 & 10 & 10 & $2 / 8$ & $3 / 7$ & 72.4 & 76.6 & 28.3 & 29.5 & Y & $\begin{array}{l}\text { PFC Sigma, } \\
\text { Depuy }\end{array}$ & $\mathrm{N}$ & NS & NS \\
\hline $\begin{array}{l}\text { K. } \\
\text { Kageyama }\end{array}$ & 2007 & 11 & 11 & $2 / 9$ & $2 / 9$ & 73.0 & 76.0 & 26.6 & 24.7 & NS & NS & NS & NS & NS \\
\hline Ta-Wei Tai & 2012 & 36 & 36 & $9 / 27$ & $8 / 28$ & 72.1 & 71.5 & 28.6 & 27.9 & Y & Genesis II or U2 & NS & NS & NS \\
\hline Hakan Ledin & 2012 & 25 & 23 & $\begin{array}{l}10 / \\
15\end{array}$ & $9 / 14$ & 70.0 & 71.0 & 29.0 & 28.0 & Y & $\begin{array}{l}\text { NexgenCR, } \\
\text { Zimmer }\end{array}$ & NS & $\begin{array}{l}\text { Low-molecular- } \\
\text { weight }\end{array}$ & NS \\
\hline David Liu & 2014 & 10 & 10 & $7 / 3$ & $9 / 1$ & 67.0 & 70.0 & 25.6 & 27.1 & Y & NS & Y & NS & NS \\
\hline Ashir Ejaz & 2014 & 33 & 31 & $\begin{array}{l}18 / \\
15\end{array}$ & $\begin{array}{l}17 / \\
14\end{array}$ & 68.0 & 68.0 & 25.0 & 25.0 & Y & $\begin{array}{l}\text { NexgenCR, } \\
\text { Zimmer }\end{array}$ & Y & Rivaroxaban & Tranexamic \\
\hline Ashir Ejaz & 2015 & 31 & 31 & $\begin{array}{l}16 / \\
15\end{array}$ & $\begin{array}{l}17 / \\
14\end{array}$ & 68.3 & 68.2 & 25.1 & 25.2 & Y & NS & Y & NS & NS \\
\hline A. Douglas & 2016 & 28 & 28 & $\begin{array}{l}16 / \\
12\end{array}$ & $\begin{array}{l}16 / \\
12\end{array}$ & 62.0 & 62.0 & 29.0 & 29.0 & Y & NS & $N$ & Y & NS \\
\hline
\end{tabular}

$T$ tourniquet, $N T$ no tourniquet

Four of the included studies [19, 24-26] reported the volume of postoperative blood loss. Postoperative blood loss was measured by calculating the postoperative blood drainage volumes. Pooled data showed no significant difference between the groups in terms of postoperative blood loss $(\mathrm{WMD}=24.07 \mathrm{~mL} ; 95 \% \mathrm{CI},-246.14$ to 294.28; $n=197 ; P=0.86 ; I^{2}=86 \%$ ), as shown in Fig. 4 .

Three studies $[17,19,21]$ reported data on total blood loss. Total blood loss means the sum of intraoperative and postoperative blood loss. No significant difference was observed between the tourniquet and no tourniquet groups in terms of postoperative blood loss $(\mathrm{WMD}=$ $17.56 \mathrm{~mL} ; 95 \% \mathrm{CI},-140.44$ to $175.57 ; n=98 ; P=0.83$; $\left.I^{2}=82 \%\right)$, as shown in Fig. 5.

There were three studies $[22,24,25]$ that met the inclusion criteria and provided data on calculated blood loss. Pooled data showed that calculated blood loss was significantly less in the tourniquet group $(\mathrm{WMD}=-$

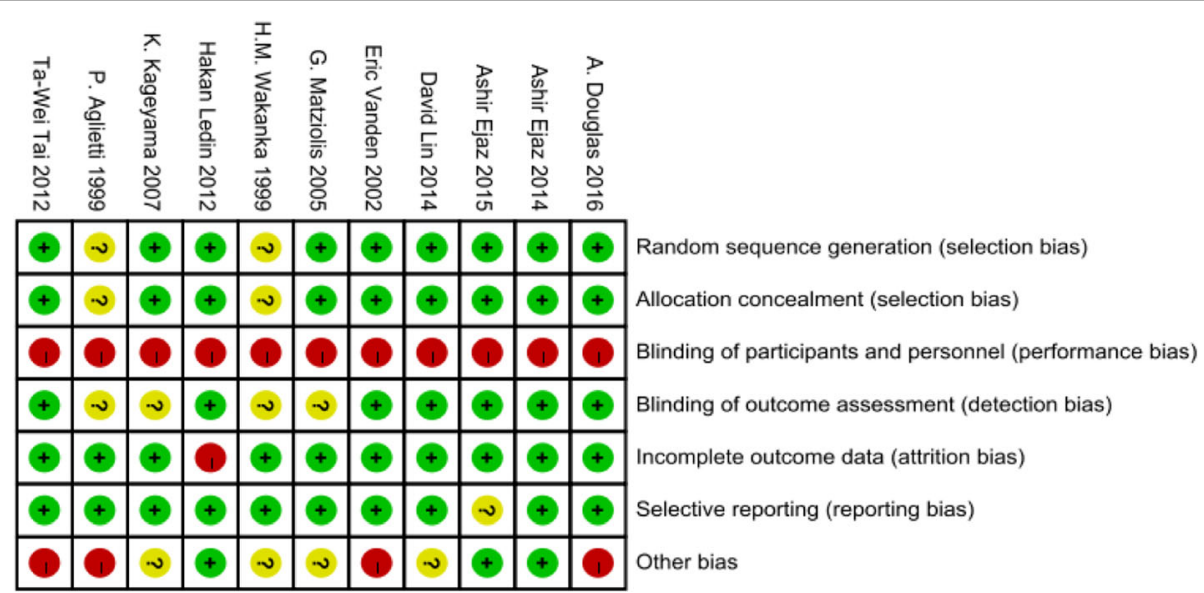

Fig. 2 Risk of bias summary. Green indicates that the criterion is satisfied. Yellow indicates that it is unclear whether the criterion is satisfied or not. Red indicates that the study did not meet the criterion 


\begin{tabular}{|c|c|c|c|c|c|c|c|c|c|c|}
\hline \multirow[b]{2}{*}{ Study or Subgroup } & \multicolumn{3}{|c|}{ Tourniquet } & \multicolumn{3}{|c|}{ No Tourniquet } & & \multirow{2}{*}{$\begin{array}{l}\text { Mean Difference } \\
\quad \text { IV. Random, } 95 \% \mathrm{Cl}\end{array}$} & \multirow{2}{*}{\multicolumn{2}{|c|}{$\begin{array}{l}\text { Mean Difference } \\
\text { IV. Random, } 95 \% \mathrm{Cl}\end{array}$}} \\
\hline & Mean & SD & Total & Mean & SD & Total & Weight & & & \\
\hline A. Douglas 2016 & 83.92 & 25.85 & 28 & 155.77 & 62.57 & 28 & $23.4 \%$ & $-71.85[-96.93,-46.77]$ & $=$ & \\
\hline Ashir Ejaz 2014 & 140 & 32.7 & 33 & 280 & 52 & 31 & $23.7 \%$ & $-140.00[-161.44,-118.56]$ & - & \\
\hline K. Kageyama 2007 & 177 & 157 & 11 & 347 & 197 & 11 & $9.9 \%$ & $-170.00[-318.87,-21.13]$ & & \\
\hline P. Aglietti 1999 & 350 & 12 & 10 & 482 & 97.4 & 10 & $19.6 \%$ & $-132.00[-192.82,-71,18]$ & $\rightarrow$ & \\
\hline Ta-Wei Tai 2012 & 25.6 & 30.9 & 36 & 243.1 & 73.1 & 36 & $23.3 \%$ & $-217.50[-243.42,-191.58]$ & - & \\
\hline Total $(95 \% \mathrm{Cl})$ & & & 118 & & & 116 & $100.0 \%$ & $-143.55[-204.59,-82.52]$ & & \\
\hline $\begin{array}{l}\text { Heterogeneity: } \mathrm{Tau}^{2}= \\
\text { Test for overall effect: }\end{array}$ & $\begin{array}{l}3977.92 \\
Z=4.61\end{array}$ & $\begin{array}{l}; \mathrm{Chi}^{2}= \\
(\mathrm{P}<0 .\end{array}$ & $\begin{array}{l}62.90 \\
00001)\end{array}$ & $\mathrm{df}=4(\mathrm{P}$ & $<0.00$ & $01) ; 1^{2}$ & $=94 \%$ & & $\begin{array}{ccc}-500 & -250 & 0 \\
\text { Favours [Tourniquet] }\end{array}$ & $\begin{array}{lll}0 & 250 & 500 \\
\text { Favours [No Tourniquet] }\end{array}$ \\
\hline
\end{tabular}

$125.41 \mathrm{~mL} ; 95 \% \mathrm{CI},-193.26$ to $-57.56 ; n=200 ; P=$ $\left.0.0003 ; I^{2}=26 \%\right)$. The results are presented as a forest plot (Fig. 6).

There was no significant difference between the tourniquet and no tourniquet groups in terms of transfusion rate among five studies [18, 22, 25-27]. The pooled data $\left(\mathrm{RR}=1.56 ; 95 \% \mathrm{CI}, 0.63\right.$ to $3.88 ; n=222 ; P=0.34 ; I^{2}=$ $0 \%)$ are presented in a forest plot (Fig. 7).

Three studies $[23,24,27]$ provided data on the rate of DVT occurrence. However, any significant difference failed to be detected. The pooled data $(\mathrm{RR}=2.19 ; 95 \%$ CI, 0.50 to $\left.9.48 ; n=221 ; P=0.30 ; I^{2}=0 \%\right)$ are presented in a forest plot (Fig. 8).

The operation time was able to be extracted from ten included studies [17-22, 24-27]. The forest plot of operation time showed that a significant difference existed between the two groups. Tourniquet use significantly decreased the operation time of TKA (WMD $=-1.08$; $95 \%$ $\mathrm{CI},-1.50$ to $\left.-0.66 ; n=464 ; \quad P<0.00001 ; I^{2}=0 \%\right)$ (Fig. 9).

\section{Discussion}

The main finding of the current meta-analysis was that using a tourniquet could significantly decrease the volume of intraoperative blood loss and the calculated blood loss. However, using a tourniquet did not significantly decrease postoperative blood loss, total blood loss, the rate of transfusion, or the rate of DVT in TKA surgery. The operation time with a tourniquet was significantly shorter than that without a tourniquet. However, the mean difference in operation time between using a tourniquet and not using a tourniquet was small.
The result showing that a tourniquet effectively reduced intraoperative blood loss was consistent with the result of previous meta-analyses [28, 29] (intraoperative blood loss: - 161.13 [-203.52, - 118.74], 295 to $631 \mathrm{~mL}$, $88.06-450.39,279.82$ to 116.60$)$. Controlling intraoperative blood loss during TKA has at least two benefits: (1) it can provide a bloodless field of view and (2) it might be beneficial for bone cement to be able to penetrate bone trabeculae, which may contribute to increased stability of the prosthesis [30]. These benefits are the main reasons that surgeons choose to use tourniquets.

Furthermore, the necessity of a tourniquet is still debatable. Our meta-analysis confirmed that tourniquets can effectively decrease intraoperative blood loss but cannot decrease total blood loss. However, Alcelik et al. and Tai et al. [4, 31] found that the use of a tourniquet reduced the total blood loss by reducing intraoperative blood loss. However, some included studies in their analyses contained patients with rheumatoid arthritis, prosthesis revision, or osteonecrosis [32, 33]. Moreover, some included studies were nonrandomized control studies [34]. These confounders might result in bias and made the conclusions inconsistent with those of our study. In this meta-analysis, we only chose the studies that excluded these confounders, and we chose to include studies in which all patients underwent TKA for primary osteoarthritis. Therefore, the conclusions of our study should be more reliable.

\section{Postoperative drainage}

Postoperative drainage volume might be influenced by many factors. The methods of drain use can significantly

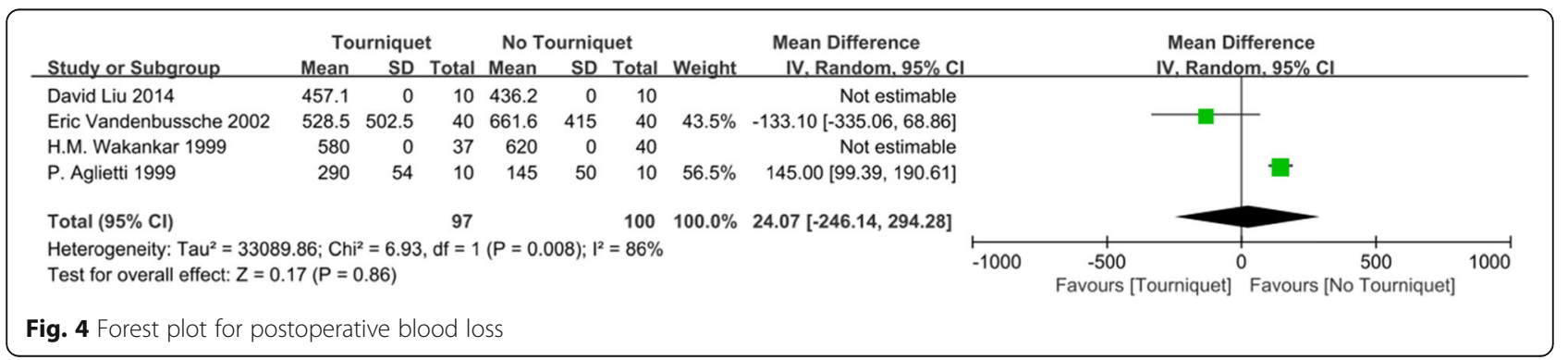




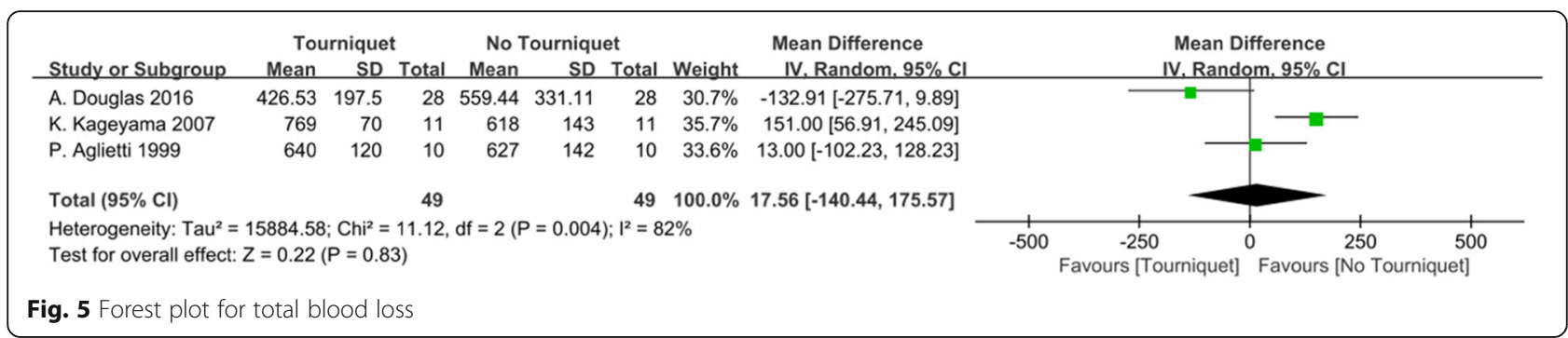

influence postoperative drainage volume. Stucinskas et al. and Shen et al. found the 4-h clamped drainage after TKA reduced the volume of postoperative drainage [35, 36].

Raleigh et al. concluded that clamping drains intermittently resulted in significantly less postoperative drainage than that observed with continuous suction drainage [37]. Park et al. found that intraarticular tranexamic acid administration plus 30-min drain clamping also significantly reduced postoperative drainage [38].

The use of a suction drain is another factor influencing postoperative drainage volume. According to Vandenbussche's study, the blood drainage volume could reach $420-530 \mathrm{~mL}$ with the use of a suction drain [24]. Furthermore, according to the study by Aglietti et al., the blood drainage volume was only $290 \mathrm{~mL}$ without suction [19].

Our study found that the use of a tourniquet did not affect postoperative drainage volume. However, there were no similar patterns with the use of drainages in the included studies. Moreover, postoperative drainage might be affected by other factors, such as different hemostasis and anticoagulant methods. Therefore, the effect of a tourniquet on postoperative drainage volume needs to be further confirmed by more high-quality studies.

\section{Calculated blood loss}

It was thought that calculated blood loss was more accurate than measured blood loss [39, 40]. Calculated blood loss contains recessive blood loss, which is believed to be caused by red blood cells entering the interstitial spaces [41]. The volume of calculated blood loss might be more than twice that of measured blood loss $[13,42]$. Our study found that tourniquet use significantly reduced calculated blood loss. This outcome is different from previous findings. In contrast, Alcelik et al. thought that a tourniquet may slightly increase calculated blood loss, but there was no significant difference [4]. In addition, other studies had similar conclusions [28, 29, 43]. However, some included studies in the previous meta-analysis contained patients with rheumatoid arthritis, which might introduce major confounders to the results. According to Harvey's study, the application of a tourniquet may increase fibrinolytic activity [32]. Rheumatoid arthritis patients might be more sensitive to tourniquet injuries, and their volume of postoperative blood loss might be more than that from ordinary patients. However, for patients with osteoarthritis, tourniquets can reduce the time of wound bleeding and reduce the extent of red blood cell infiltration into tissue space, reducing the amount of recessive blood loss, thereby reducing the calculated blood loss.

\section{Transfusion rate}

Despite the fact that calculated blood loss and intraoperative blood loss were significantly different, our metaanalysis found no significant differences in the rate of transfusions between the tourniquet group and the no tourniquet group. This finding was consistent with the results of other meta-analyses. Tourniquets are not the only factor affecting blood transfusion rates. The blood transfusion standards in the included studies were not uniform and were influenced by the patient's age, general physical conditions, and basic disease states. So, although the current findings are consistent, more high-

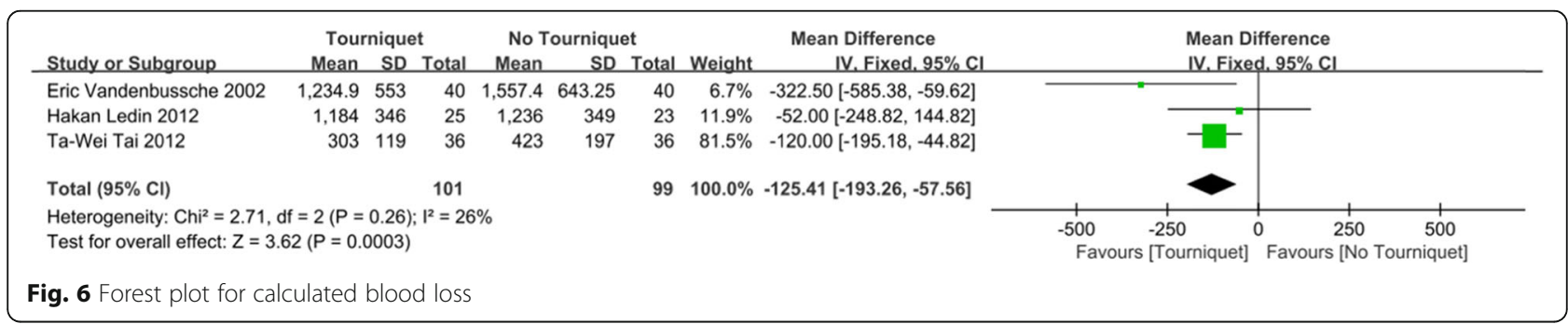




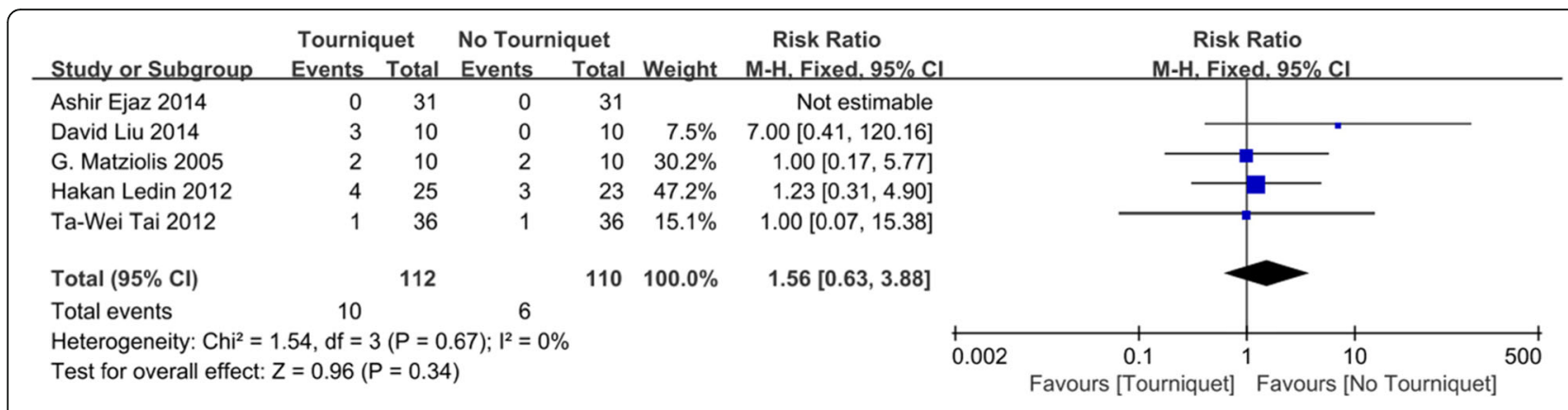

Fig. 7 Forest plot for transfusion rate

quality studies are still needed to confirm whether tourniquets affect blood transfusion rates.

\section{Operation time}

Our study confirmed that tourniquet use was effective in reducing operative time compared with no tourniquet use. A tourniquet can provide surgeons with a bloodless surgery field and facilitate the clear identification of anatomical structures during surgery, which might be conducive to shortening the operation time. Moreover, if the operation is performed without a tourniquet, more electrocoagulation and wound irrigation may be required during the operation. These additional procedures can increase the operation time. Zhang et al. determined that a tourniquet could reduce the operation time [28], which is consistent with our findings. However, it is worth noting that their study included patients with rheumatoid arthritis and patients undergoing revision surgery. These confounders might lead to biased results, because revision surgery requires additional surgical procedures, and rheumatoid patients might need more electrocoagulation. Our study excluded patients with rheumatoid arthritis and patients undergoing revisions, so the result of this meta-analysis is more reliable.

\section{Incidence of DVT}

In this study, we found that the use of a tourniquet did not significantly increase the incidence of DVT. This finding was consistent with previous studies [29, 43, 44]. However, tourniquets are a potential risk factor for
DVT. Parmet et al. found that the incidence of DVT with a tourniquet was 5.33 times higher than that with no tourniquet [45]. In addition, the incidence of DVT is affected by other factors, such as the administration of anticoagulant drugs, time until rehydration, and tourniquet pressure. In our meta-analysis, some included studies used anticoagulants [17, 19], and some did not use anticoagulants [18]. The same problem existed in other meta-analysis studies [44, 46]. These differences in inclusion criteria may lead to inconsistent results from different studies. Therefore, further high-quality studies are needed to confirm whether tourniquet use is an independent risk factor for DVT.

\section{Other complications}

Because of insufficient data in the included literature, the current meta-analysis could not confirm whether there was a difference between using a tourniquet and not using a tourniquet in the incidence rates of some outcomes (i.e., wound hematoma, wound oozing, skin blistering, muscle injury, nerve palsy, and PE). The use of tourniquets might lead to more superficial infections of wounds [47]. However, Wakankar et al. determined that there was no difference between using tourniquets and not using tourniquets in terms of wound complications [23]. According to our study, $13 \mathrm{~min}$ was the longest time that was saved by the application of a tourniquet, and some RCTs found that a shorter operation time did not decrease the incidence of postoperative complications. Therefore, whether the shortening of

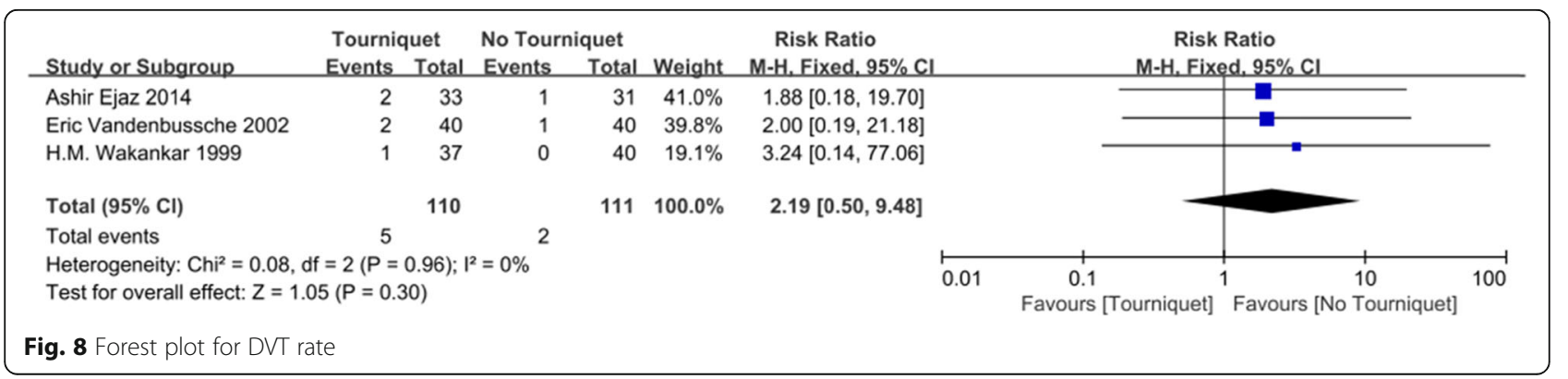




\begin{tabular}{|c|c|c|c|c|c|c|c|c|c|c|c|c|c|}
\hline \multirow[b]{2}{*}{ Study or Subgroup } & \multicolumn{3}{|c|}{ Tourniquet } & \multicolumn{3}{|c|}{ No Tourniquet } & & \multirow{3}{*}{$\begin{array}{l}\text { Mean Difference } \\
\text { IV. Fixed, } 95 \% \mathrm{Cl}\end{array}$} & & \multirow{2}{*}{\multicolumn{2}{|c|}{$\begin{array}{l}\text { Mean Difference } \\
\text { IV. Fixed, } 95 \% \mathrm{Cl}\end{array}$}} & & \\
\hline & Mean & SD & Total & Mean & SD & Total & Weight & & & & & & \\
\hline A. Douglas 2016 & 61.88 & 10.77 & 28 & 64.88 & 9.48 & 28 & $0.6 \%$ & & & + & & & \\
\hline Ashir Ejaz 2014 & 70 & 1 & 33 & 71 & 0.75 & 31 & $95.4 \%$ & $-1.00[-1.43,-0.57]$ & & & & & \\
\hline Ashir Ejaz 2015 & 69.5 & 5.3 & 31 & 71.3 & 4.5 & 31 & $3.0 \%$ & $-1.80[-4.25,0.65]$ & & & & & \\
\hline David Liu 2014 & 83 & 0 & 10 & 96 & 0 & 10 & & Not estimable & & & & & \\
\hline Eric Vandenbussche 2002 & 151 & 35 & 40 & 156.5 & 30 & 40 & $0.1 \%$ & $-5.50[-19.79,8.79]$ & & & & & \\
\hline G. Matziolis 2005 & 85 & 10 & 10 & 93 & 17.5 & 10 & $0.1 \%$ & $-8.00[-20.49,4.49]$ & & & & & \\
\hline Hakan Ledin 2012 & 85 & 30 & 25 & 81 & 23 & 23 & $0.1 \%$ & $4.00[-11.05,19.05]$ & & & & & \\
\hline K. Kageyama 2007 & 163 & 21 & 11 & 158 & 23 & 11 & $0.1 \%$ & $5.00[-13.41,23.41]$ & & & & & \\
\hline P. Aglietti 1999 & 90 & 18 & 10 & 96 & 11 & 10 & $0.1 \%$ & $-6.00[-19.07,7.07]$ & & & & & \\
\hline Ta-Wei Tai 2012 & 72 & 8.4 & 36 & 78.3 & 14.9 & 36 & $0.6 \%$ & $-6.30[-11.89,-0.71]$ & & - & & & \\
\hline Total $(95 \% \mathrm{Cl})$ & & & 234 & & & 230 & $100.0 \%$ & $-1.08[-1.50,-0.66]$ & & $\bullet$ & & & \\
\hline $\begin{array}{l}\text { Heterogeneity: Chi }=7.27 \text {, } \\
\text { Test for overall effect: } Z=5\end{array}$ & $\begin{array}{l}\text { If }=8(P \\
01(P<0\end{array}$ & $\begin{array}{r}=0.51) \\
.00001\end{array}$ & $1^{2}=0 \%$ & & & & & & -20 & $\begin{array}{cc}1 & 1 \\
-10 & 0 \\
\text { Favours [Tourniquet] }\end{array}$ & Favours [N & $\begin{array}{l}10 \\
\text { No Tourniquet] }\end{array}$ & 20 \\
\hline
\end{tabular}

operation time can decrease wound complications is still unclear at present $[7,29,48]$. Preoperative coexisting diseases, such as atherosclerosis, blood hypercoagulability, poor blood glucose, or uncontrolled blood pressure, were associated with the increasing incidence of postoperative complications. Tourniquets should be avoided in these patients, but we could not identify such patients from the current study. Patients with coexisting diseases in an RCT might affect the physician's judgment on whether tourniquets cause certain complications [11]. Therefore, the current meta-analysis could not confirm whether the use of a tourniquet would increase the incidence of some surgical complications (i.e., wound hematoma, wound oozing, skin blistering, muscle injury, nerve palsy, and PE.)

\section{Limitations}

The current meta-analysis has several limitations. Firstly, in some studies, the time for loosening the tourniquet was different. Some studies $[19,22]$ loosened the tourniquet before closing the incision, and some [24-26] loosened the tourniquet after applying the elastic bandage. Secondly, some studies differed in drainage patterns, hemostasis, and anticoagulation regimens, and this might result in a bias. Thirdly, in the included studies, none of the surgeons were blinded.

\section{Conclusions}

According to the current meta-analysis, using a tourniquet may significantly decrease intraoperative blood loss, calculated blood loss, and the operation time, but tourniquet use did not significantly decrease the rate of blood transfusion or the rate of DVT in TKA. More research is needed to determine if there are fewer complications without the use of tourniquets in TKA surgery.

\section{Abbreviations}

Cl: Confidence interval; SD: Standard deviation; DVT: Deep vein thrombosis; PE: Pulmonary embolism; RCTs: Randomized controlled trials; TKA: Total knee arthroplasty; WMD: Weighted mean difference

\section{Acknowledgments}

Not applicable.

\section{Authors' contributions}

DFC participated in the entire procedure, including the literature search, data extraction, statistical analysis, and drafting of the manuscript. QHF and PS participated in the literature search, data extraction, and statistical analyses. $\mathrm{HHZ}$ and $\mathrm{SH}$ contributed to the statistical analysis, revision of the manuscript, and preparation of the figures and tables. All authors read and approved the final manuscript.

\section{Funding}

The authors declare that they have no sources of funding for the research.

\section{Availability of data and materials}

Data sharing is not applicable to this article as no datasets were generated or analyzed during the current study.

Ethics approval and consent to participate

Not applicable.

Consent for publication

Not applicable.

\section{Competing interests}

The authors declare that they have no competing interests.

Received: 6 January 2019 Accepted: 16 October 2019

Published online: 08 November 2019

\section{References}

1. Berry DJ, Bozic KJ. Current practice patterns in primary hip and knee arthroplasty among members of the American Association of Hip and Knee Surgeons. J Arthroplast. 2010;25(6 Suppl):2-4.

2. Jarolem $\mathrm{KL}$, Scott DF, Jaffe $\mathrm{WL}$, et al. A comparison of blood loss and transfusion requirements in total knee arthroplasty with and without arterial tourniquet. Am J Orthop (Belle Mead NJ). 1995:24(12):906-9.

3. Parvizi J, Diaz-Ledezma C. Total knee replacement with the use of a tourniquet: more pros than cons. Bone Joint J. 2013:95-b(11 Suppl A):133-4.

4. Alcelik I, Pollock RD, Sukeik M, et al. A comparison of outcomes with and without a tourniquet in total knee arthroplasty: a systematic review and meta-analysis of randomized controlled trials. J Arthroplast. 2012; 27(3):331-40.

5. Schnettler T, Papillon $\mathrm{N}$, Rees $\mathrm{H}$. Use of a tourniquet in total knee arthroplasty causes a paradoxical increase in total blood loss. J Bone Joint Surg Am. 2017:99(16):1331-6.

6. Palmer SH, Graham G. Tourniquet-induced rhabdomyolysis after total knee replacement. Ann R Coll Surg Engl. 1994;76(6):416-7.

7. Carroll K, Dowsey M, Choong P, et al. Risk factors for superficial wound complications in hip and knee arthroplasty. Clin Microbiol Infect. 2014;20(2): $130-5$. 
8. Weber $A B$, Worland $R L$, Jessup $D E$, et al. The consequences of lateral release in total knee replacement: a review of over 1000 knees with follow up between 5 and 11 years. Knee. 2003;10(2):187-91.

9. Rama KR, Apsingi S, Poovali S, et al. Timing of tourniquet release in knee arthroplasty. Meta-analysis of randomized, controlled trials. J Bone Joint Surg Am. 2007;89(4):699-705.

10. Li B, Wen $Y, W u H$, et al. The effect of tourniquet use on hidden blood loss in total knee arthroplasty. Int Orthop. 2009;33(5):1263-8.

11. Kvederas G, Porvaneckas N, Andrijauskas A, et al. A randomized doubleblind clinical trial of tourniquet application strategies for total knee arthroplasty. Knee Surg Sports Traumatol Arthrosc. 2013;21(12):2790-9.

12. Pollock $M$, Fernandes RM, Becker $L A$, et al. What guidance is available for researchers conducting overviews of reviews of healthcare interventions? A scoping review and qualitative metasummary. Syst Rev. 2016;5(1):016-0367.

13. Gross JB. Estimating allowable blood loss: corrected for dilution. Anesthesiology. 1983;58(3):277-80.

14. Higgins JP, Altman DG, Gotzsche PC, et al. The Cochrane Collaboration's tool for assessing risk of bias in randomised trials. Bmj. 2011;18(343).

15. Higgins JP, Thompson SG, Deeks JJ, et al. Measuring inconsistency in metaanalyses. Bmj. 2003;327(7414):557-60.

16. Chiappelli F, Kasar VR, Balenton N, et al. Quantitative consensus in systematic reviews: current and future challenges in translational science. Bioinformation. 2018;14(2):86-92.

17. Kageyama K, Nakajima Y, Shibasaki M, et al. Increased platelet, leukocyte, and endothelial cell activity are associated with increased coagulability in patients after total knee arthroplasty. J Thromb Haemost. 2007;5(4):738-45.

18. Matziolis G, Drahn T, Schroder JH, et al. Endothelin-1 is secreted after total knee arthroplasty regardless of the use of a tourniquet. J Orthop Res. 2005 23(2):392-6.

19. Aglietti $P$, Baldini $A$, Vena $L M$, et al. Effect of tourniquet use on activation of coagulation in total knee replacement. Clin Orthop Relat Res. 2000;371:16977.

20. Ejaz A, Laursen AC, Kappel A, et al. Tourniquet induced ischemia and changes in metabolism during TKA: a randomized study using microdialysis. BMC Musculoskelet Disord. 2015;16:326.

21. Dennis DA, Kittelson AJ, Yang CC, et al. Does tourniquet use in TKA affect recovery of lower extremity strength and function? A randomized trial. Clin Orthop Relat Res. 2016;474(1):69-77.

22. Tai TW, Chang CW, Lai KA, et al. Effects of tourniquet use on blood loss and soft-tissue damage in total knee arthroplasty: a randomized controlled trial. J Bone Joint Surg Am. 2012;94(24):2209-15.

23. Wakankar HM, Nicholl JE, Koka R, et al. The tourniquet in total knee arthroplasty. A prospective, randomised study. J Bone Joint Surg Br. 1999; 81(1):30-3.

24. Vandenbussche $E$, Duranthon LD, Couturier M, et al. The effect of tourniquet use in total knee arthroplasty. Int Orthop. 2002;26(5):306-9.

25. Ledin H, Aspenberg P, Good L. Tourniquet use in total knee replacement does not improve fixation, but appears to reduce final range of motion. Acta Orthop. 2012;83(5):499-503.

26. Liu D, Graham D, Gillies K, et al. Effects of tourniquet use on quadriceps function and pain in total knee arthroplasty. Knee Surg Relat Res. 2014;26(4): 207-13.

27. Ejaz A, Laursen AC, Kappel A, et al. Faster recovery without the use of a tourniquet in total knee arthroplasty. Acta Orthop. 2014;85(4):422-6.

28. Zhang W, Li N, Chen S, et al. The effects of a tourniquet used in total knee arthroplasty: a meta-analysis. J Orthop Surg Res. 2014;9(1):13.

29. Tie K, Hu D, Qi Y, et al. Effects of tourniquet release on total knee arthroplasty. Orthopedics. 2016;39(4):e642-50.

30. Leon-Munoz VJ, Lison-Almagro AJ, Hernandez-Garcia CH, et al. Silicone ring tourniquet versus pneumatic cuff tourniquet in total knee arthroplasty surgery: a randomised comparative study. J Orthop. 2018;15(2):545-8.

31. Tai TW, Lin CJ, Jou IM, et al. Tourniquet use in total knee arthroplasty: a meta-analysis. Knee Surg Sports Traumatol Arthrosc. 2011;19(7):1121-30.

32. Harvey EJ, Leclerc J, Brooks CE, et al. Effect of tourniquet use on blood loss and incidence of deep vein thrombosis in total knee arthroplasty. J Arthroplast. 1997:12(3):291-6

33. Tetro AM, Rudan JF. The effects of a pneumatic tourniquet on blood loss in total knee arthroplasty. Can J Surg. 2001;44(1):33-8.

34. Fukuda A, Hasegawa M, Kato K, et al. Effect of tourniquet application on deep vein thrombosis after total knee arthroplasty. Arch Orthop Trauma Surg. 2007;127(8):671-5.
35. Stucinskas J, Tarasevicius S, Cebatorius A, et al. Conventional drainage versus four hour clamping drainage after total knee arthroplasty in severe osteoarthritis: a prospective, randomised trial. Int Orthop. 2009;33(5):1275-8.

36. Shen PC, Jou IM, Lin YT, et al. Comparison between 4-hour clamping drainage and nonclamping drainage after total knee arthroplasty. J Arthroplast. 2005;20(7):909-13.

37. Raleigh $\mathrm{E}$, Hing $\mathrm{CB}$, Hanusiewicz AS, et al. Drain clamping in knee arthroplasty, a randomized controlled trial. ANZ J Surg. 2007;77(5):333-5.

38. Park JH, Choi SW, Shin EH, et al. The optimal protocol to reduce blood loss and blood transfusion after unilateral total knee replacement: low-dose IATXA plus 30-min drain clamping versus drainage clamping for the first $3 \mathrm{~h}$ without IA-TXA. J Orthop Surg. 2017;25(3):2309499017731626.

39. Lotke PA, Faralli VJ, Orenstein EM, et al. Blood loss after total knee replacement. Effects of tourniquet release and continuous passive motion. J Bone Joint Surg Am. 1991;73(7):1037-40.

40. Levy AS, Marmar E. The role of cold compression dressings in the postoperative treatment of total knee arthroplasty. Clin Orthop Relat Res. 1993;297:174-8

41. Erskine JG, Fraser C, Simpson R, et al. Blood loss with knee joint replacement. J R Coll Surg Edinb. 1981;26(5):295-7.

42. Bourke DL, Smith TC. Estimating allowable hemodilution. Anesthesiology. 1974:41(6):609-12

43. Zhang $\mathrm{P}$, Liang $\mathrm{Y}, \mathrm{He} \mathrm{J}$, et al. Timing of tourniquet release in total knee arthroplasty: a meta-analysis. Medicine (Baltimore). 2017:96(17):e6786.

44. Huang Z, Ma J, Zhu Y, et al. Timing of tourniquet release in total knee arthroplasty. Orthopedics. 2015:38(7):445-51.

45. Parmet JL, Horrow JC, Berman AT, et al. The incidence of large venous emboli during total knee arthroplasty without pneumatic tourniquet use. Anesth Analg. 1998;87(2):439-44

46. Zhang W, Liu A, Hu D, et al. Effects of the timing of tourniquet release in cemented total knee arthroplasty: a systematic review and meta-analysis of randomized controlled trials. J Orthop Surg Res. 2014;9:125.

47. Abdel-Salam A, Eyres KS. Effects of tourniquet during total knee arthroplasty. A prospective randomised study. J Bone Joint Surg Br. 1995;77(2):250-3.

48. Willis-Owen CA, Konyves A, Martin DK. Factors affecting the incidence of infection in hip and knee replacement: an analysis of 5277 cases. J Bone Joint Surg Br. 2010;92(8):1128-33.

\section{Publisher's Note}

Springer Nature remains neutral with regard to jurisdictional claims in published maps and institutional affiliations.

Ready to submit your research? Choose BMC and benefit from:

- fast, convenient online submission

- thorough peer review by experienced researchers in your field

- rapid publication on acceptance

- support for research data, including large and complex data types

- gold Open Access which fosters wider collaboration and increased citations

- maximum visibility for your research: over $100 \mathrm{M}$ website views per year

At $\mathrm{BMC}$, research is always in progress.

Learn more biomedcentral.com/submissions 